\title{
Analysis of Free Flow Speed on Urban Road
}

\author{
Made Mahendra, Harnen Sulistio, Ludfi Djakfar and Achmad Wicaksono
}

\begin{abstract}
Congestion has become a problem of traffic on urban road segments in several major cities in Indonesia, it will have a negative impact on the driver or users of the road due to the longer travel time. Congestion resulting in economic and immaterial losses such as cause stress due to fatigue, and congestion in critical condition can result in excessive fuel consumption and air pollution are also higher. Before the congestion is in critical condition there must be performed Indicator, to be able to determine the handling step early, because handling the congestion problem will be more difficult to handle, if the congestion is already in critical condition. The congestion performance indicator is a derivative of a delay which delays the speed of the vehicle free-flow speed due to side barriers on the road. Free-flow speed is an important characteristic for capacity and level-of-service (LOS) analysis of urban road. The objective of this study is to develop models delay form magnitude of results analysis estimating free-flow speed. Many generic factors like weather, environment, vehicles, roadway characteristics, driver and traffic streams either singly or in combination influence the free flow speed. The quantitative measures of these factors are desirable for reliable free-flow speed measurement and system design. Characteristics of diverse urban roads and high side friction characteristics in major urban cities in Indonesia greatly determine the value of vehicle free current velocities, which will determine the parameter of delay values that occur where this can be a performance indicator approach in defining the performance of an urban road segment in Indonesia. This research was conducted in several road segments and part of an urban road segment in Mataram city, Provence of Nusa Tenggara Barat. Primary data traffic is done with video camera, with variation of time and road segment, in order to get variation of traffic characteristic and the variation side frictions characteristic at the same time. With the data will be analyzed relationship between variations characteristics above components with speed data in 5 minutes Time slice on the range of traffic data in under saturated condition. Free Flow speed (FV) vehicles will be analyzed from the relationship between Speed $(V)$ and traffic flow $(Q)$ as well as variations in side friction (SF) characteristics obtained at time slices at the same time. The result of analysis shows the influence of side friction characteristics that vary in magnitude such as: parking vehicles, vehicles in and out of the road segment, the number of pedestrians, and vehicles stopped. The number of motorcycles in the traffic flow also affects the value of free flow speed analysis. The results of free flow speed analysis above also contrast with the results of free flow speed analysis model IHCM 1997. Type
\end{abstract}

Made Mahendra is with the Mataram University, Mataran , Indonesai. He is now with the Department of Civil Engineering, Mataram University (email: mahendramade@unram.ac.id).

Harnen Sulistio,Prof., is with the Civil Engineering Department, University of Brawijaya.

Ludfi Djakfar is with the Civil Engineering Department, University of Brawijaya (e-mail: Ldjakfar@ub.ac.id)

Achmad Wicaksono is with the Civil Engineering Department, University of Brawijaya . and side friction quantity resulting from the analysis of free flow speed was later can be used as the basis of policy expenditure in order to create a policy in preventing the occurrence of critical congestion. From the analysis of this free-flow speed can be used in model performance approach urban road due to the influence of delay.

Index Terms - Congestion, urban road, free flow speed, side friction, IHCM 1997

\section{INTRODUCTION}

$T$ RANSPORT problems such as congestion are a major problem in urban road traffic. Traffic jams that occur greatly disrupt the activities of the population. Congestion will have a negative impact on drivers or road users due to longer travel time. Congestion caused economic losses as well as immaterial such as stress caused by the length travel time. The congestion of causes from various interconnected lives such as inadequate discipline, the growth of vehicles that can not be matched by the growth of road infrastructure. The development of medium-class cities in Indonesia in recent years has made significant progress both in terms of economy and in terms of population growth. Of course, this will have an impact on the users of increasing transportation facilities, and the need for transportation infrastructure is also experiencing developments that should be balanced with adequate infrastructure development. The city of Mataram as one of the cities of medium classification began to face the above problems. Some net networks have experienced delay problems due to high side barriers, in the central area of activity or economy (CBD).

Free Flow Speed (FV) is defined as the velocity at zero current, ie the speed the driver will choose if driving a motor vehicle without being affected by another motor vehicle (IHCM, 1997). Free Flow Speed has been observed through field data collection, where the relationship between free flowspeed with geometric and environmental conditions is determined by the regression method. Light-vehicle free flowspeed has been selected as the basic criterion for road segment performance at traffic flow $(Q)=0$. Free flow-speed for heavy vehicles and motorcycles is also given as a reference. The free flow-speed for passenger cars is usually $10-15 \%$ higher than other types of light vehicles.

As an indicator, the Indonesian Highway Capacity Manual (IHCM, 1997), is a manual for analysis, planning, design, and operation of road traffic facilities for Indonesia, is a product of empirical research conducted in some places considered to represent the condition of traffic characteristics in the region Indonesia. The value of the resulting analysis parameters is 
not an absolute number, may change from time to time and from location to location. The time period since the publication of the condition experienced by the road transport infrastructure and its users, both in terms of quantity and quality, is no longer appropriate to the traffic characteristics and the condition of the infrastructure at the time. The condition is expected to change the analysis parameters in IHCM. Mismatch analysis parameters can produce technical design results that may be over / under design. [3]. The results are found that the estimated capacity and speed of IHCM 1997 analysis is too high. The effects of the side friction were higher than IHCM's estimated 1997. When side barriers were too high there was a significant difference between the actual, actual and predicted capacity of IHCM 1997 [1].

The city of Mataram as one of the cities of medium classification began to face the above problems. Some net networks have experienced delay problems due to high side barriers, in the central area of activity or economy (CBD). The derivation of the above exposure is the flow of traffic on the road network of a city, this is often overlooked in handling it so that Indonesia only has the Indonesia Road Capacity Manual 1997 (IHCM, 1997), and until now the evaluation of the manual is very less. In some researches and applications in the field of this manual several times have been done, especially in cities that began to develop, with the aim will not solve the problem after a problem in movement on the network, both it intersection and on the segment. The basic parameters of performance evaluation can be either speed, delay, or in the degree of saturation of the language of simple congestion. Due to the characteristics of the traffic of cities developed in Indonesia, the high side barriers, and control functions of the geometric networks (segments and intersections) are less in line with the hierarchy. In MKJI 1997 it has been included but needs to be analyzed in more detail from each of the above factors, not in the simple classification (very low, low, medium, high, and very high).

There are several free-flow speed definitions such as: as the desired average speed is adopted by the driver when not limited by other vehicles in low currents under various road conditions [4]( (HCM, 2010; Polgar et al., 2013; Tettamanti and Varga, 2014). have other definitions that vary depending on the context or application, there are two important definitions given here. First, the free-flow speed on urban roads is the speed at which vehicles travel under low volume conditions when all signals in urban roads are green for the entire journey.

When vehicle interaction and traffic control factors do not exist, the speed chosen by the average driver is called the freeflow speed (FFS). Secondly, FFS is the average speed of the traffic flow when traffic volume is low enough that the driver is unaffected by the presence of other vehicles and when the intersection control traffic is absent or far enough to have no effect on the speed of choice (HCM, 2010). Also, traffic volume is an important factor in influencing free flow conditions. Theoretically, FFS should be at the speed at which this flow is zero. To overcome this difficulty, it is generally measured at very low flow rates. Furthermore, FFS is essential in the analysis of traffic flow for incidents and congestion and hence factors that affect value must be studied carefully to understand the behavior of traffic and this analysis also helps in sensitivity analysis.

The three main factors (a) the path of geometry and conditions (b) the driver's characteristics / attributes and (c) the environment, are parameters to influence American urban road values of traffic flow and highways [7]. In addition to above road roughness also has a significant effect on free-flow velocity [9]. driver attributes and vehicle characteristics are also one of the major factors in the estimation of urban freeflow speed. Young drivers, passenger occupancy rates, vehicle age and travel destinations have a higher impact on speed, parked vehicles vertical or horizontal along the road negatively impacting free-flow speed [6].

Of the many definitions and models of free-flow speed resulting from the different characteristics of traffic flows, the condition of urban road network, this study emphasizes the analysis of free flow-speed of IHCM 1997 compared with the regression analysis of traffic flow (Q) relationship and speed (V) due to side friction of urban roads with urban type medium (case study Mataram City- NTB-Indonesia)

\section{LITERATURE REVIEW}

Transportation problems are a lot of in the developing world and some of them are already in a very critical stage. The problems that occur are not only caused by the limited system of transportation infrastructure, but also by the rapid urbanization, the limited resources and funds, the quality and quantity of data related to transportation, as well as the low level of discipline, and the lack of planning and control systems, transportation becomes increasingly severe, [5]. It can be seen that many of these infrastructure systems are not functioning efficiently (operating under capacity), resulting from high side side constraints on the side of the road such as pedestrian use by peddlers, parking on the road, access to and out of roads, which will certainly reduce the capacity of the road and will lead to a decrease in speed for vehicle traffic through it. The definition of traffic according to the Law of the Republic of Indonesia No.14 of 1992 is the motion of vehicles, people and animals in the road traffic space that has a sense of infrastructure intended for the movement of vehicles, people and or goods in the form of roads and supporting facilities. While the definition of traffic congestion is a situation or condition obstructed or even cessation of traffic caused by the number of vehicles exceeding the capacity of the road.

\section{A. Congestion}

The problem of congestion is the most common problem in big cities in Indonesia. This problem usually arises in cities with the population of more than 2 million people such as Jakarta, Bandung, Surabaya, Medan, and Jogyakarta. One of the main causes of urban congestion is urbanization. As soon as it develops, Indonesia experiences a transition from an 
agrarian country to an industrial country. Many industries are built in urban areas, this has become one of the attractions to stay in urban areas. Congestion is also caused by the limited road network, the total area of the road network is very low compared to the total area of urban areas that must be served.

\section{B. Definition of Roads and Urban Roads in Indonesian}

The definition of a road is a land transport infrastructure covering all sections of the road, including auxiliary buildings, and its equipment that are torn down for traffic, different ground surface, above ground level, below ground and / or water, and above the water surface, fire and road wiring (UU No. 38 of 2006 on roads). Road segment according to According to Indonesia Road Capacity Manual (IHCM) 1997 is defined as the length of the road between or not influenced by the signaled intersection or the main non-signal intersection and has almost the same characteristics. The point at which the characteristic of the road significantly changes to the segment boundary even though there is no adjacent intersection. Small changes in geometric need not be questioned (eg the difference in traffic lane width less than $0.5 \mathrm{~m}$ ), especially if the change is only partial.

According to the Indonesian Highway Capacity Manual (IHCM) 1997, urban roads are a segment of roads that have permanent and continuous development along the whole or almost roads, minimum on one side of the road, whether in the form of land developments or not. Roads in or near urban centers with a population of over 100,000 are always classified in this group. Roads in urban areas with populations of less than 100,000 are also classified in this group if they have permanent and continuous roadside developments. Ironically, with limited road network capacity, many road segments are not functioning properly. Another factor causing congestion in urban areas is the increasing tendency of transportation service users to use private vehicles compared to public transport.

\section{Free-Flow Speed (FV)}

There are several free current speed definitions such as: as the desired average speed is adopted by the driver when not limited by other vehicles in low currents under various road conditions (HCM, 2010; Polgar et al., 2013; Tettamanti and Varga, 2014). have other definitions that vary depending on the context or application, there are two important definitions given here. First, the free-flow speed on urban roads is the speed at which vehicles travel under low volume conditions when all signals in urban roads are green for the entire journey.

When vehicle interaction and traffic control factors do not exist, the speed chosen by the average driver is called the freeflow speed (FFS). Secondly, FFS is the average speed of the traffic flow when traffic volume is low enough that the driver is unaffected by the presence of other vehicles and when the intersection control traffic is absent or far enough to have no effect on the speed of choice (HCM, 2010). Also, traffic volume is an important factor in influencing free-flow conditions. Theoretically, FFS should be at the speed at which this flow is zero. To overcome this difficulty, it is generally measured at very low flow rates. Furthermore, FFS is essential in the analysis of traffic flow for incidents and congestion and hence factors that affect value must be studied carefully to understand the behavior of traffic and this analysis also helps in sensitivity analysis. There are three main factors :

1. Road geometry and conditions

2. Characteristics of driver attributes and

3. Environments

Are parameters to influence American urban road values of traffic flow and highways (Lamm et al., 1990). In addition to above road roughness also has a significant effect on free-flow speed (Wang et al., 2014). driver attributes and vehicle characteristics are also one of the major factors in the estimation of urban free-flow speed. Young drivers, passenger occupancy rates, vehicle age and travel destinations have a higher impact on speed, parked vehicles vertical or horizontal along the road negatively impacting free-flow speed [8]. The free-flow speed (FV) is defined as the velocity at zero current, ie the speed the driver will choose if driving a motor vehicle without being affected by another motor vehicle [2]. Freeflow speed has been observed through field data collection, where the relationship between free-flow speed with geometric and environmental conditions is determined by the regression method. Light-vehicle free-flow speed has been selected as the basic criterion for road segment performance at flow $=0$. Free-flow speed for heavy vehicles and motorcycles are also provided for reference. The free-flow speed for passenger cars is usually $10-15 \%$ higher than other types of light a vehicles. IHCM 1997 decisive free-flow speed :

1. The theoritical average speed $(\mathrm{km} / \mathrm{h})$ of traffic whent density is zero, i.e, there are not vehicles present.

2. Speed $(\mathrm{km} / \mathrm{h})$ of a vehicles which is not restrained by any other vehicles (i.e, a speed at which drivers feel convortable travelling under the geometric, environmental, and traffic control conditions on a given road segment with no other traffic).

In IHCM 1997, the equations for the determination of freeflow speed have the following general shape :

$$
F V=\left(F V_{O}+F V_{W}\right) x F F V_{S F} x F F V_{C S}
$$

Where :

Fv : Actual free-flow speed for Light Vehicles (LV) $(\mathrm{km} / \mathrm{h})$ FVO: Base free-flow speed for ideal conditions $(\mathrm{km} / \mathrm{h})$

FVW : adjustment for carriageway width $(\mathrm{km} / \mathrm{h})$

FFVSF : adjustment factor for side friction

FFVCS : adjustment factor for city size $(\mathrm{km} / \mathrm{h})$

\section{Speed}

In collecting data uses travel speed (synonymous with journey speed) as the main measure of performance of road segments, travel speed is defined in IHCM 1997 as space mean speed of light vehicles (LV) over the road segment:

$\mathrm{V}=\mathrm{L} / \mathrm{TT}$

Where :
$\mathrm{V}$ : Space mean speed of LV $(\mathrm{km} / \mathrm{h})$

$\mathrm{L}$ : Length of segment $(\mathrm{km})$ 
TT : Mean Travel time of LV over the segment (h)

Space mean speed is the average rate based on the length of time each vehicle takes in space. The average velocity of space can be calculated by the following equation:

$$
V_{s}=\frac{n L}{\sum_{i=1}^{n} t i}
$$

Where :

Vs : average travel speed or average space velocity $(\mathrm{km} / \mathrm{h})$

$\mathrm{L}$ : display the highway segment $(\mathrm{m})$

ti : travel time of vehicle to $i$ to pass part of road $(\mathrm{h})$

$\mathrm{n}=$ number of travel times observed

\section{STUdy AREA}

For the required variation of data required a location or area that has characteristics as mentioned above with reference to IHCM 1997. One of the areas in the city of Mataram, which approached the criteria is the way Panca Usaha and Pejanggik road. Jalan Panca Usaha and Pejanggik roads were selected from the matrix of site research criteria conducted on previous studies, with Selaparang road comparison road, and Sriwijaya road in Mataram city. Jalan Panca Usaha and Pejanggik street is an urban road located in Cakranegara sub-district. The type of road on Panca Usaha Street and Pejanggik street is one way street (2/1). Cakranegara Kecamata area is one of the shopping and commercial area in Mataram City, this can be seen from the many shops in this region. At this time both sides of the road have popped up commercial activities such as the number of shops and traders on the side of the road. This resulted in many side barriers occurring on this road, such as the number of pedestrians, vehicle stops and parking spaces, motor vehicles entering and exiting to and from the roadside.

The Panca Usaha and Pejanggik road area has a road length of the length of more less $1.4 \mathrm{~km}$ and has about 32 access, about 28 from the access road has a distance adjacent to the distance between access more less $50 \mathrm{~m}$ and has high traffic flow. Viewing from it can cause many traffic conflicts on the access road. The number of vehicles entering and leaving the access road will have an impact on the performance of the declining Panca Usaha road.

The Panca Usaha and Pejanggik road area are also one of the public transportation routes of Mataram City. This can also affect the performance of this road segment in the form of the number of public transport that stopped haphazardly. So the consequence of this can cause congestion on Panca Usaha road and Pejanggik street. Situation and description of the study area can be seen in Fig..1.

From the exposure above this area can be selected as the research area, with high side barrier characteristic, also a variation of road segment also varied, it is possible to get the parameter from the research data in the form of current a variation and side barrier variation. Conditions on Jalan Panca Usaha at this time has been done to widen the road from the width of the road $6 \mathrm{~m}$ to $9 \mathrm{~m}$ and felling trees on the roadside.
From the exposure above this area can be selected as the study area, with high side friction characteristic, also the variation of road segment also the varied, it is possible to get the parameter from the research data in the form of current variation and side friction variation. The description of the Mataram city road network is parallel to the number of access roads in and out of the main road, thus causing side barriers to the main high road segment.

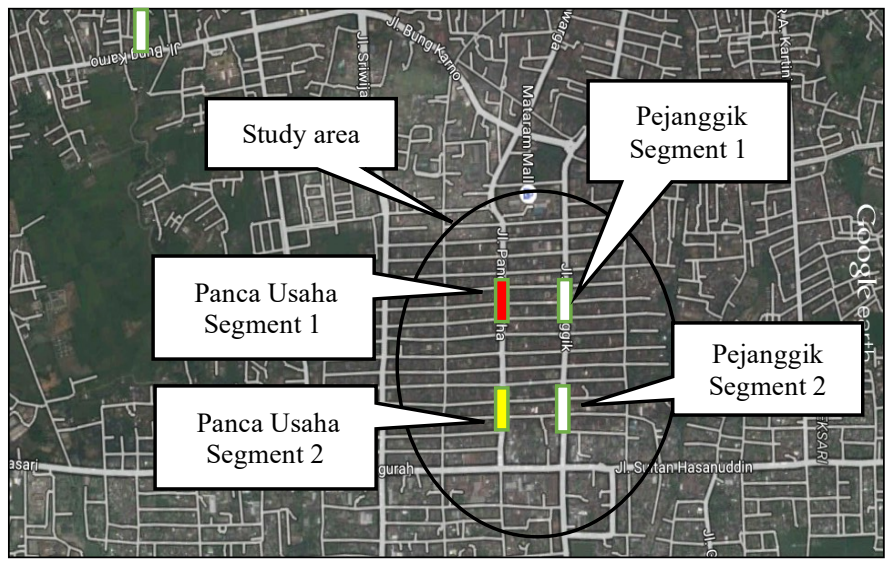

Fig.1 Study Area

The location of the study is focused on the two road segments based on the characteristics of the road segment and the variation of existing side constraints, as well as the different environmental conditions in each of the road zones that will be used as the chosen research location.

To obtain data that varies between traffic flow (Q), speed (V) and side friction (FV) in the study area is done by dividing 1 segment in 2 segment and 3 different days in one week (Monday, Saturday and week) representing work days, weekend, and holidays, and in 1 day for 2 hours each morning, noon and afternoon (time dimension) with 5 minute time slice at each observation time.

\section{DATA Collection}

Data retrieval is done by video (GoPro 4) for data between traffic flow (Q), speed (V) and side friction (FV) in the study area in the time dimension and space dimension already presented in the above section. All the collected data was collected, analyzed in the laboratory manually and tabulated with 5 minutes time slice and 75 meters for travel time data. The location-selective for study are as follows (Fig.1); by identifying in data collection and analysis with street names, road segments and data retrieval days (Panca Usaha Segment 1 week).

Data collected in the form of tables with each having code in the form of data types, segment and segment and the date and time of Taking as Table I. 
TABLE I

FORM SURVEY SIDE FRICTION

\begin{tabular}{|c|c|c|c|c|}
\hline \multicolumn{3}{|c|}{ FORM SURVEI SIDE FRICTION : } & KODE & SF \\
\hline \multicolumn{3}{|c|}{ Date/Day $\quad: 26 / 2 / 2018$ (Monday) } & Time & 00.07 \\
\hline \multicolumn{3}{|c|}{ Road $\quad$ :Panca Usaha } & weather & sunny \\
\hline \multicolumn{3}{|c|}{$\begin{array}{ll}\text { Segment } & : 1\end{array}$} & Surveyor & Ageng \\
\hline \multicolumn{3}{|c|}{ Segmen Leght $: 75$ Meter } & \multicolumn{2}{|c|}{ Supervisor } \\
\hline \multicolumn{5}{|c|}{ EVENTS NUMBER } \\
\hline \multirow[b]{2}{*}{ Time Slice (mnt) } & \multicolumn{4}{|c|}{ Side Friction tipe } \\
\hline & PSV & EEV & PED & SMV \\
\hline 5 & 2 & 23 & 0 & 1 \\
\hline 10 & 2 & 12 & 0 & 0 \\
\hline 15 & 3 & 6 & 2 & 0 \\
\hline 20 & 6 & 23 & 0 & 0 \\
\hline 25 & 5 & 4 & 1 & 0 \\
\hline 30 & 4 & 3 & 0 & 0 \\
\hline 35 & 3 & 21 & 3 & 1 \\
\hline 40 & 2 & 22 & 2 & 0 \\
\hline 45 & 4 & 12 & 0 & 0 \\
\hline 50 & 3 & 5 & 1 & 2 \\
\hline 55 & 2 & 4 & 1 & 0 \\
\hline 60 & 5 & 8 & 1 & 0 \\
\hline
\end{tabular}

For speed analysis in this research, there is two analysis of speed that is the accuracy of survey result (speed field or speed of operation) and speed in IHCM. In the field speed analysis or operational speed, the vehicle speed survey data is used. From the data then perform the analysis of the average speed of space or space mean speed (SMS) with equation (1)

The survey conducted is to calculate and record the volume of vehicle traffic by classifying it which includes nonmotorized vehicles, heavy vehicles, light vehicles, and motorcycles moving on the Panca Usaha road.

TABLE II

FORM SURVEY TRAFFIC COUNTING

\begin{tabular}{|c|c|c|c|c|}
\hline \multicolumn{3}{|c|}{ FORM SURVEI TRAFFIC COUNTING } & KODE & TC \\
\hline Date/Day & \multicolumn{2}{|c|}{ :26/2/2018 (Monday) } & Time & 00.07 \\
\hline Road & \multicolumn{2}{|c|}{ : Panca Usaha } & weather & sunny \\
\hline Segment & \multicolumn{2}{|c|}{$: 1$} & Surveyor & Patra \\
\hline Segmen Leght & \multicolumn{2}{|l|}{ :75 Meter } & Supervisor & \\
\hline \multicolumn{5}{|c|}{ TRAFFIC VOLUME } \\
\hline \multirow[b]{2}{*}{ TS (Menit) } & \multicolumn{4}{|c|}{ Traffic Element } \\
\hline & LV & $\mathrm{MC}$ & HV & UM \\
\hline 5 & 34 & 80 & 0 & 0 \\
\hline 10 & 45 & 89 & 1 & 0 \\
\hline 15 & 57 & 97 & 0 & 2 \\
\hline 20 & 45 & 110 & 0 & 0 \\
\hline 25 & 56 & 130 & 0 & 1 \\
\hline 30 & 60 & 120 & 0 & 0 \\
\hline 35 & 56 & 98 & 0 & 3 \\
\hline 40 & 45 & 88 & 0 & 2 \\
\hline 45 & 65 & 89 & 1 & 0 \\
\hline 50 & 55 & 79 & 0 & 1 \\
\hline 55 & 45 & 90 & 0 & 1 \\
\hline 60 & 34 & 87 & 0 & 1 \\
\hline
\end{tabular}

The Recording is done for every 5- minute interval for every hour of observation. Traffic data is collected for 6 hours, 2 hours each morning, noon and night, an observation which started at 06.00-16.00 WITA. The survey was conducted on
Monday, Saturday and Sunday. Data collection from video recordings can be seen in Table II.

The result the recording of survey data is made of recapitulation data table (Table III) which will be used to analyze the relationship between the traffic flow $(\mathrm{Q})$ variable and the speed $(\mathrm{V})$ in finding the free-flow speed of light vehicle (VFV) current in the field.

TABLE III

RECAPITULATION OF DATA TYPES

\begin{tabular}{|c|c|c|c|c|c|c|c|c|c|c|c|}
\hline \multicolumn{12}{|c|}{ recentuanow rons } \\
\hline \multicolumn{3}{|c|}{$2 \operatorname{as} / 2 / \operatorname{sas}$ (Mondar) } & & & & & & & & \multicolumn{2}{|c|}{ Time: } \\
\hline Pna: & \multicolumn{2}{|c|}{ Mna uath } & & & & & & & & \multicolumn{2}{|c|}{\begin{tabular}{|l} 
wea \\
\end{tabular}} \\
\hline Eegmens & & & & & & & & & \multicolumn{2}{|c|}{ Surcion: } \\
\hline Segrenteght : 79 Me: & \multicolumn{2}{|c|}{ : rovier } & & & & & & & & \multicolumn{2}{|c|}{ Sugeniser: } \\
\hline \multicolumn{12}{|c|}{ RECAPITUAATION DATA TYPE } \\
\hline \multirow{2}{*}{ Time Slice (Menit) } & \multicolumn{5}{|c|}{ Traffic Flow (Q) } & & peed (V) & \multicolumn{4}{|c|}{ Side Friction(SF) } \\
\hline & เv & MC & HN & un & Tot Ven & Tota pau & $(\mathrm{km} / \mathrm{n})$ & PSV & EN & FED & $5 \mathrm{M}$ \\
\hline s & 94 & $\because 0$ & 0 & 0 & $i x$ & 74,00 & 428 & 2 & 2 & 0 & $\therefore$ \\
\hline 20 & 49 & \pm & 2 & 0 & $i=$ & $20: 0$ & 2400 & 2 & 3 & 0 & 0 \\
\hline is & $y$ & $n$ & 0 & 2 & is & $2005: 00$ & 2290 & 2 & 8 & 2 & 0 \\
\hline 20 & 49 & 20 & 0 & 0 & is & 2000,00 & $28: 0$ & 0 & $\because$ & 0 & 0 \\
\hline $2 \mathrm{~s}$ & 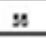 & 1200 & 0 & 2 & 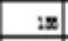 & $m, 20$ & $2=$ & 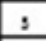 & 4 & $\therefore$ & 0 \\
\hline 90 & $\infty$ & 20 & 0 & 0 & $: 5$ & 20,00 & $29: 0$ & 4 & 2 & 0 & 0 \\
\hline is & $\because$ & $n$ & 0 & 9 & is & 200,00 & 2420 & $:$ & $n$ & 2 & $:$ \\
\hline 20 & 4 & $z$ & 0 & 2 & in & 32,00 & 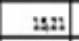 & 2 & 23 & 2 & 0 \\
\hline 48 & 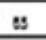 & $n$ & 2 & 0 & in & 210,80 & $24: 3$ & 4 & a & 0 & 0 \\
\hline 90 & 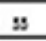 & $n$ & 0 & 2 & is & $24: 50$ & $24: 2$ & I & 8 & 2 & 2 \\
\hline$s$ & 4 & $\infty$ & 0 & 2 & $=$ & $n 0,0$ & 242 & 2 & 4 & $:$ & 0 \\
\hline 60 & 94 & $y$ & 0 & $:$ & 2 & $n: 0$ & nas & 9 & 8 & 1 & 0 \\
\hline 69 & $z$ & as & 0 & 0 & $\mathrm{z}$ & 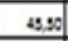 & 2450 & 5 & 10 & 0 & 0 \\
\hline$n$ & $g_{4}$ & g4 & 0 & 2 & \pm & 32,00 & 200 & $\therefore$ & 2 & 2 & 0 \\
\hline$\pi$ & 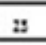 & 8 & 2 & 2 & 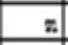 & 980 & nus & 8 & 8 & 2 & 0 \\
\hline 80 & 94 & $n$ & 2 & 2 & $i s$ & 81,20 & $29: 0$ & 2 & 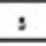 & 1 & 0 \\
\hline is & 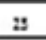 & 80 & 0 & 2 & : & 00,0 & $2: 28$ & 8 & 3 & 2 & 2 \\
\hline$x$ & $n$ & $n$ & 0 & 0 & $i x$ & 7200 & 200 & 4 & 8 & 0 & 0 \\
\hline 28 & 94 & $n$ & 0 & 0 & $2:$ & $n, 00$ & 2985 & 8 & 23 & 0 & 0 \\
\hline 200 & 4 & 8 & 0 & 0 & at & $n$ & 2908 & 4 & 31 & 0 & $:$ \\
\hline
\end{tabular}

tic flux density $B$ or magnetic field strength symbolized as $\mu_{0} H$. Use the center dot to separate compound units, e.g., "A $\mathrm{m}^{2} . "$

\section{RESULtS}

\section{A. IHCM Analysis Results 1997}

Free current velocity is the speed $(\mathrm{km} / \mathrm{h})$ of a vehicle that is not influenced by other vehicles, i.e. the speed at which the rider feels comfortable traveling, in geometric conditions, environmental and traffic settings, on a road segment where there is no other vehicle.

It should be noted that light-free-flow speed are used as a key measure of performance in this analysis. The steps of free current velocity calculation (FV) can be seen as follows:

1. The free current velocity (FV) for light vehicles can be calculated by equation (1) :

$$
F V=\left(F V_{O}+F V_{W}\right) x F F V_{S F} x F F V_{C S}
$$

2. Determine the speed of the free flow-free base (FVO) of light vehicles using Table 2.5 IHCM 1997. For the Panca Usaha Road section has two-lane two-lane road type (2/1), the value of free light base velocity $(\mathrm{FVo}) 57 \mathrm{~km} / \mathrm{hr}$. 
3. Determine the free flow rate adjustment factor for the width of the traffic lane $\left(\mathrm{FV}_{\mathrm{W}}\right)$ using Table 2.6 of IHCM 1997. For the Panca Usaha Road section has a two-lane one-way (2/1) road type and the effective traffic line width (WC) per lane of $4.50 \mathrm{~m}$ based on the width of the Panca Usaha road traffic, the $\mathrm{FV}_{\mathrm{W}}$ value is $-2 \mathrm{~km} / \mathrm{h}$.

4. Determine the free-flow rate adjustment factor for side barriers $\left(\mathrm{FFV}_{\mathrm{SF}}\right)$ using Table 2.7 of IHCM 1997 because Panca Usaha Road is a shoulder-driven road. For the Panca Usaha road section has a one-way two-lane road type $(2 / 1)$, the effective shoulder width (WS) of $\leq 0.5 \mathrm{~m}$ based on the width of the Panca Usaha road traffic path of the existing condition, side friction class $\left(\mathrm{S}_{\mathrm{FC}}\right)$ is very high, then obtained $\mathrm{FFV}_{\mathrm{SF}}$ value of 0.73 .

5. Determine the free flow rate adjustment factor for city size (FFV $\left.{ }_{\mathrm{CS}}\right)$ using Table 2.9 of IHCM 1997. Based on data obtained from BPS of Mataram City in 2013, the population of Mataram City is 519,641 inhabitants, the value of $\mathrm{FFV}_{\mathrm{CS}}$ is 0.93 .

6. Determine the free flow velocity (FV) for light vehicles with equation (1)

$$
\begin{aligned}
F V & =\left(F V_{0}+F V_{w}\right) \times F F V_{S F} \times F F_{C s} \\
& =(57-2) \times 0,73 \times 0,93 \\
& =37,34 \mathrm{Km} / \mathrm{h}
\end{aligned}
$$

\section{B. Results Field data analysis}

The result of data analysis above can be seen in the traffic between traffic flow (Q) in 5 minutes with light speed data velocity (VLV) in 5 minutes. The result is obtained from the timing data of each data from 2 road segments and two segments in each road segment. The graph of the relationship can be selected in the Fig. 2 .

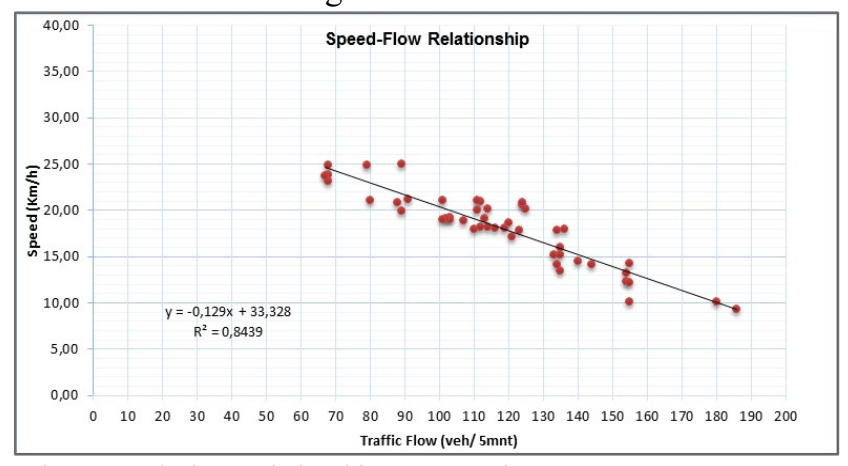

Fig. 2 Speed-Flow Relationship Panca Usaha Seg.1

From Fig. 2. we get the relationship between the traffic flow $(\mathrm{Q})$ in the 5-minute timer with light velocity data $\left(\mathrm{V}_{\mathrm{LV}}\right)$ data within 5 minutes on the Panca Usaha segment 1 in the equation:

$$
\mathrm{Y}=-0.129+33,328
$$

With $\mathrm{R}^{2}=0.8438$

From the equation if assumed the free-flow speed (FV) occurs when the traffic flow $(\mathrm{Q})=0$ or $\mathrm{X}=0$ then the value of $\mathrm{FV}$ is $33.328 \mathrm{~km} / \mathrm{h}$. are:

The results of the road and other segment analysis

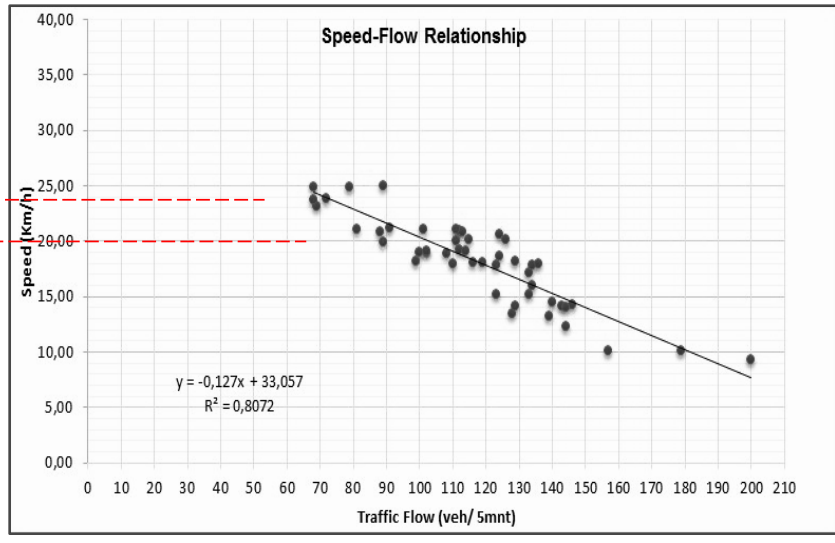

Fig.3 Speed-Flow Relationship Panca Usaha Seg.2

From Fig. 3, we get the relationship between the traffic flow $(\mathrm{Q})$ in the 5-minute timer with light velocity data $\left(\mathrm{V}_{\mathrm{LV}}\right)$ data within 5 minutes on the Panca Usaha segment 2 in the equation:

$$
\mathrm{Y}=-0.127+33,057
$$

With $\mathrm{R}^{2}=0.8072$

From the equation if assumed the free-flow speed (FV) occurs when the traffic flow $(\mathrm{Q})=0$ or $\mathrm{X}=0$ then the value of $\mathrm{FV}$ is $33.057 \mathrm{~km} / \mathrm{h}$.

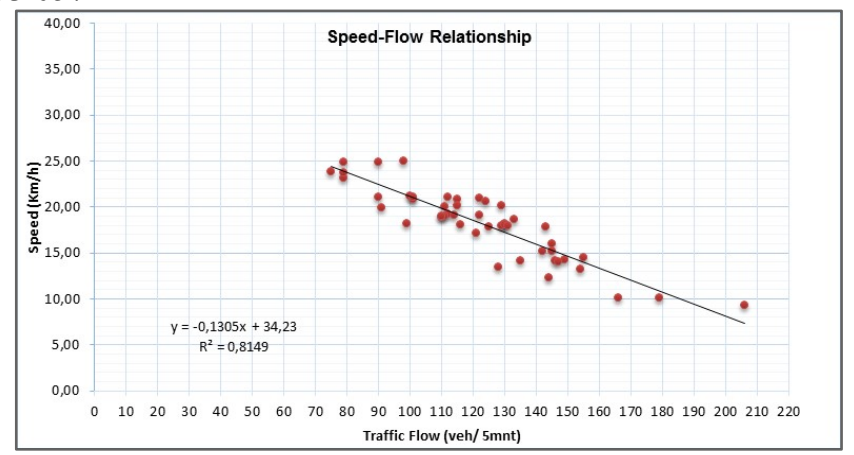

Fig. 4 Speed-Flow Relationship Pejanggik Seg.1

From Fig. 4, we get the relationship between the traffic flow $(\mathrm{Q})$ in the 5-minute timer with light velocity data $\left(\mathrm{V}_{\mathrm{LV}}\right)$ data within 5 minutes on the Pejanggik segment 1 in the equation:

$$
\begin{aligned}
& \mathrm{Y}=-0.1305 \mathrm{X}+34,23 \\
& \text { With } \mathrm{R}^{2}=0.8149
\end{aligned}
$$

From the equation if assumed the free-flow speed (FV) occurs when the traffic flow $(\mathrm{Q})=0$ or $\mathrm{X}=0$ then the value of $\mathrm{FV}$ is $33.057 \mathrm{~km} / \mathrm{h}$. 


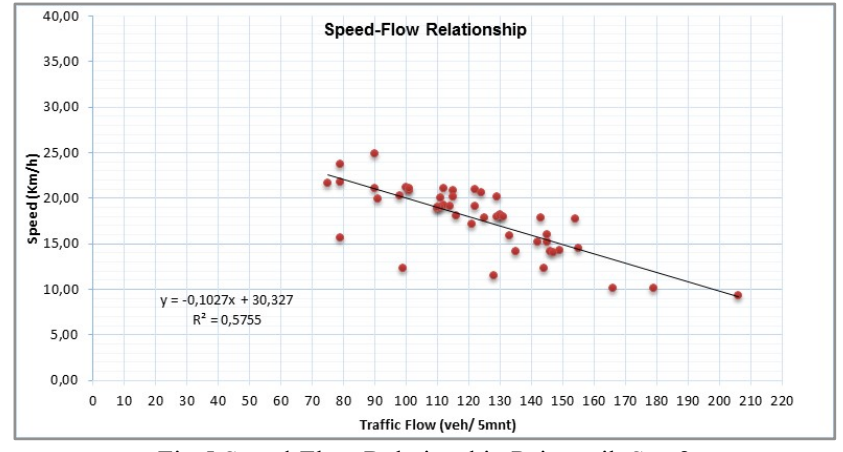

Fig.5 Speed-Flow Relationship Pejanggik Seg.2

From Fig. 5, we get the relationship between the traffic flow $(\mathrm{Q})$ in the 5-minute timer with light velocity data $\left(\mathrm{V}_{\mathrm{LV}}\right)$ data within 5 minutes on the Pejanggik segment 2 in the equation:

$$
\begin{aligned}
& \mathrm{Y}=-0.1027 \mathrm{X}+30,327 \\
& \text { With } \mathrm{R}^{2}=0.5755
\end{aligned}
$$

From the equation if assumed the free-flow speed (FV) occurs when the traffic flow $(\mathrm{Q})=0$ or $\mathrm{X}=0$ then the value of $\mathrm{FV}$ is $30,327 \mathrm{~km} / \mathrm{h}$.

\section{CONCLUSION}

The free-flow speed (FV) for light vehicles (LV) from field data analysis and the 1997 IHCM analysis shows a higher value of free-flow speed generated from the graph of the relationship between traffic flow (Q) and light vehicle speed (LV) ).

The magnitude and equation of analysis of IHCM 1997 analysis on each segment and segment are: Analysis of IHCM 1997 value of light vehicle FV $(\mathrm{LV})=37.340 \mathrm{~km} / \mathrm{h}$ this value is the same for all segment and road because it has entered in a multiplication factor of analysis.
a. Panca Usaha segment $1=\quad \mathrm{Y}=-0.129 \mathrm{X}+$ $33,328, \mathrm{R}^{2}=0,8438, \quad \mathrm{FV}(\mathrm{LV})=33,328 \mathrm{Km} / \mathrm{h}$.
b. Panca Usaha segment $2=\quad \mathrm{Y}=-0.127 \mathrm{X}+$ $33,057, \mathrm{R}^{2}=0,8072, \quad \mathrm{FV}(\mathrm{LV})=33,057 \mathrm{Km} / \mathrm{h}$.
c. Pejanggik segment $1=\quad \mathrm{Y}=-0.131 \mathrm{X}+$ $34,320, \mathrm{R}^{2}=0,8149, \quad \mathrm{FV}(\mathrm{LV})=34,320 \mathrm{Km} / \mathrm{h}$.
d. Pejanggik segment $2=\quad \mathrm{Y}=-0.103 \mathrm{X}+$ $30,327, \mathrm{R}^{2}=0,8438, \quad \mathrm{FV}(\mathrm{LV})=30,327 \mathrm{Km} / \mathrm{h}$.

The effect of side friction (SF) is indicated to affect the free-flow speed in this study is seen from the different results of the two different road segments and road segments on each of the road segments. It is worth noting the factor of motor vehicles and also the dominant factor of the type of side friction (SF). which is high against the value of free flow velocity on urban roads,

Need to be evaluated or modification against the IHCM 1997, gradually due to the condition of the field data validation parameters, as well as views of the traffic characteristic and performance Model approach solution specifically conceived for urban Roads, Road chain-based or with the Segment-based.

\section{REFERENCES}

[1] A. Munawar, "Speed and Capacity for Urban Roads, Indonesian Experience", $6^{\text {th }}$ International Symposium on Highway Capacity and Quality of Service, Stockholm, Sweden June 28 - July 1, 2011

[2] Directorate General of Highways Republic Indonesia, "Indonesian Highway Capacity Manual (IHCM)", Jakarta, Indonesia, 1997

[3] E.Kusnandar, "Updating Manual Kapasitas Jalan Indonesia (MKJI) 1997”, Research and Development Center Road Bridge, Bandung Indonesia, 2009

[4] HCM, Higway Capasity Manual, Transportation Reseaarch Board, 2010

[5] O. Z. Tamin, Perencanaan Pemodelan Transportasi, Institut Teknologi Bandung (ITB), Bandung, Indonesia, 1984

[7] R.Dowling, W. Kitteison, J. Zegeer, A. Skabardonis, "Planning Technigues to Estimate Speeds and Service Volume for Applications". NCHRP Report 387, Transportation Research Board. 12-15, 1977.

[8] R. Lamm, E.M. Choueiri, T. Mailaender, "Compassion of Operating Speeds on Dry and Wet Pavements of Two- Lane Rural Highways". Transportation Research Board. 1990.

[9] T. Wang, J. Harvey, J. Lea, C. Kim, Impact of Pavement Roughness on Vehicle Free-Flow Speed. Journal of Transportation Engineering 9, 140 (2014) DOI: 101061/(ASCE)TE 1943-5436000689. 